\title{
Bucky-bowls. A general approach to benzocorannulenes: synthesis of mono-, di- and tri-benzocorannulenes
}

\section{Goverdhan Mehta* and P. V. V. Srirama Sarma}

Department of Organic Chemistry, Indian Institute of Science, Bangalore, 560012 India.

E-mail:diroff@admin.iisc.ernet.in

\section{Received (in Cambridge, UK) 8th November 1999, Accepted 16th November 1999}

We outline a conceptually simple and general route to bowlshaped benzocorannulenes based on readily assembled PAHs which on flash vacuum pyrolysis result in the sequential formation of a five- and six-membered ring; following this approach, syntheses of mono-, di- and tribenzocorannulenes have been achieved.

As a part of our continuing interest in the synthesis of $\mathrm{C}_{60}$ fullerene (bucky-ball) and its fragments (bucky-bowls), $, 1,2$ we became interested in developing a synthetic approach to pentabenzocorannulene 1 en route (see transannular bridging indicated in 1) to the 'deep-bowl' $2, \mathrm{C}_{40} \mathrm{H}_{10} \cdot{ }^{3}$ Bowl-shaped $\mathbf{1}$ and 2 represent $2 / 3$ of the carbon content of $\mathrm{C}_{60}$ with eleven and sixteen rings, respectively, constituting a dominant crosssection on the fullerene surface. Both $\mathbf{1}$ and $\mathbf{2}$ evoke considerable synthetic interest and are formidable objectives. As a prelude to efforts towards $\mathbf{1}$ and $\mathbf{2}$, we have developed a new and
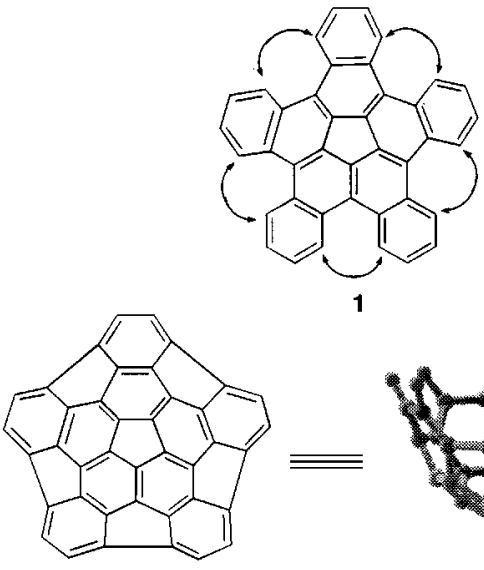

2

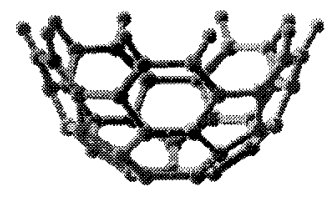

AM1 minimised structure

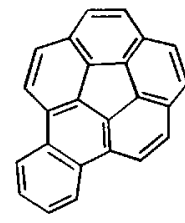

3

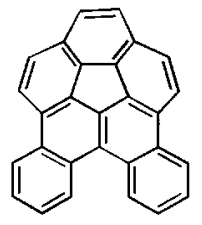

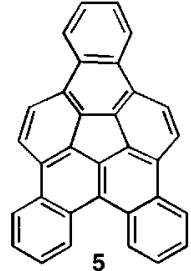

general synthetic route to benzoannulated corannulenes in which an appropriately constructed aromatic array upon flash vacuum pyrolysis (FVP) undergoes two-fold $\mathrm{C}-\mathrm{C}$ bond formation involving cyclodehydrogenation to generate a five-membered ring, followed by insertion of vinylidene carbene or equivalent species to form a six-membered ring. Herein, we report the synthesis of mono-, di- and tri-benzocorannulenes 3-5.

Our approach to benzocorannulene $\mathbf{3}$ emanated from 13methylbenzo[ $g]$ chrysene 7 , readily available from 9-methylphenanthrene 6 through a tactical modification of the reported

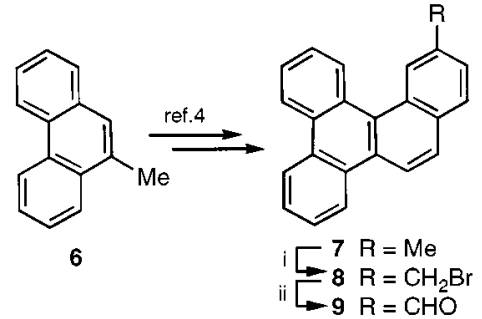

Scheme 1 Reagents and conditions: i, NBS, AIBN, $\mathrm{CCl}_{4}, 73 \%$; ii, $\left(\mathrm{Bu}_{4} \mathrm{~N}\right)_{2} \mathrm{Cr}_{2} \mathrm{O}_{7}, \mathrm{CHCl}_{3}, 76 \%$.

procedure. ${ }^{4}$ The methyl group in 7 was oxidised to the required aldehyde 9 in two steps via the intermediate bromide $\mathbf{8}$ (Scheme 1). The aldehyde functionality in 9 was then elaborated to 10-12 having active functionalities, which on thermal activation under FVP conditions were expected to result in the projected twofold cyclization. Indeed, FVP of 10-12 furnished 3, albeit in low yields characteristic of such reactions (Scheme 2). ${ }^{2}$ Benzocorannulene 3 was readily identified through its spectral characteristics (UV, 2D NMR, mass). 5,6

Our approach to dibenzocorannulene $\mathbf{4}$ originated from 5-methylbenzo[ $c]$ phenanthrene $\mathbf{1 3}$, in turn readily accessible from commercial 2-methylnaphthalene. ${ }^{7}$ Naphthoannulation on 13 through the intermediacy of the Wittig salt 14 and photocyclization of the resulting stilbene derivative $\mathbf{1 5}$ led to 13-methyldibenzo[c,p]chrysene 16 (Scheme 3). The methyl

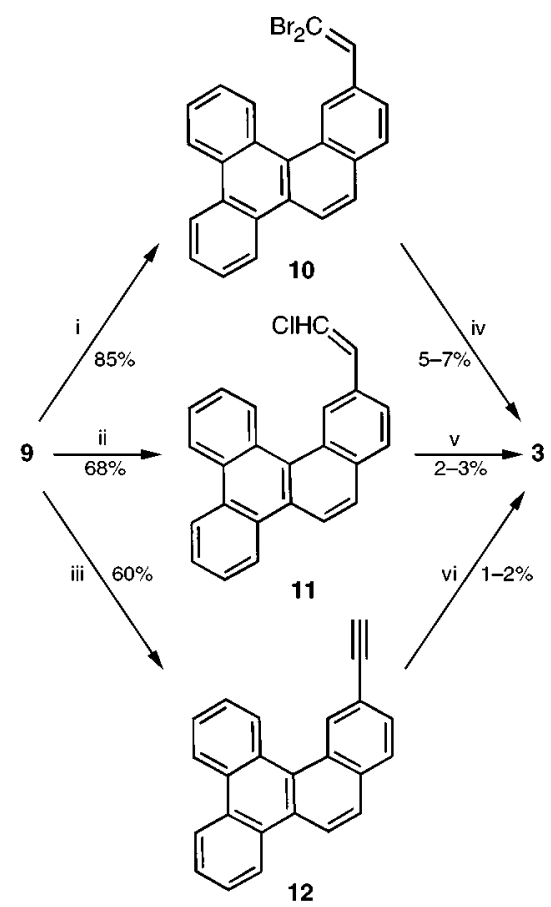

Scheme 2 Reagents and conditions: i, $\mathrm{CBr}_{4}, \mathrm{PPh}_{3}, \mathrm{Zn}, \mathrm{CH}_{2} \mathrm{Cl}_{2}, 85 \%$; ii, $\mathrm{ClCH}_{2} \mathrm{PPh}_{3} \mathrm{Cl}$, But $\mathrm{BK}, 0.5$ h, 68\%; iii, $\mathrm{ClCH}_{2} \mathrm{PPh}_{3} \mathrm{Cl}$, But $\mathrm{BuK}^{\mathrm{t}} 2 \mathrm{~h}, 60 \%$; iv, FVP, $1150{ }^{\circ} \mathrm{C}, 5-7 \%$; v, FVP, $1150{ }^{\circ} \mathrm{C}, 2-3 \%$; vi, FVP, $1150{ }^{\circ} \mathrm{C}, 1-2 \%$. 


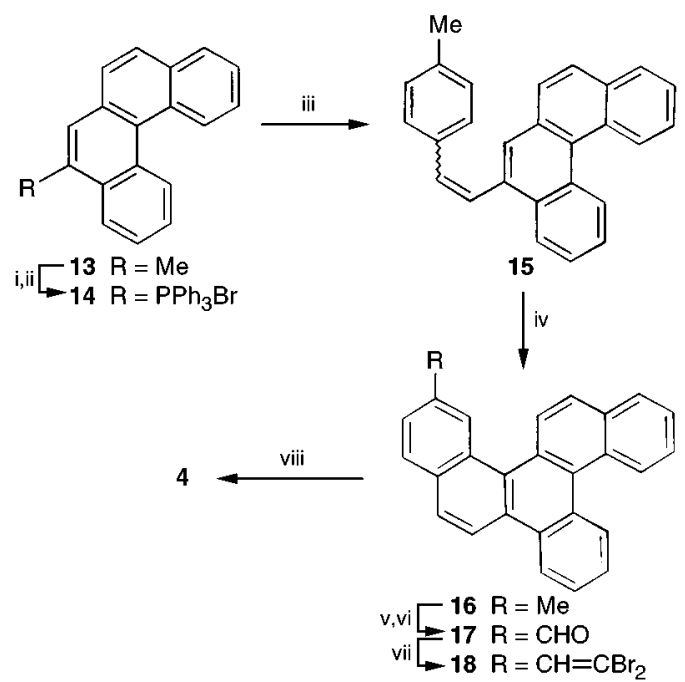

Scheme 3 Reagents and conditions: i, NBS 99\%; ii, $\mathrm{PPh}_{3}, \mathrm{C}_{6} \mathrm{H}_{6}, 79 \%$; iii, $p-\mathrm{MeC}_{6} \mathrm{H}_{4} \mathrm{CHO}, \mathrm{Cs}_{2} \mathrm{CO}_{3}$, $\mathrm{Pr} \mathrm{OH}, 80 \%$; iv, $h v, \mathrm{I}_{2}, \mathrm{C}_{6} \mathrm{H}_{6}$, propylene oxide, $65 \%$; v, NBS, $\mathrm{CCl}_{4}, 44 \%$; vi, $\left(\mathrm{Bu}_{4} \mathrm{~N}\right)_{2} \mathrm{Cr}_{2} \mathrm{O}_{7}, \mathrm{CHCl}_{3}, 77 \%$; vii, $\mathrm{CBr}_{4}, \mathrm{PPh}_{3}$, $\mathrm{Zn}, \mathrm{CH}_{2} \mathrm{Cl}_{2}, 85 \%$; viii, $\mathrm{FVP}, 1150{ }^{\circ} \mathrm{C}, 5-7 \%$.

group in $\mathbf{1 6}$ was oxidised to the aldehyde $\mathbf{1 7}$ and in the light of the relatively more efficient conversion $\mathbf{1 0} \rightarrow \mathbf{3}$ was further transformed to the hexacyclic gem-dibromoalkene 18, the desired FVP precursor. On thermal activation 18 underwent the expected double cyclization to furnish the new dibenzocorannulene $\mathbf{4}$ and was fully characterised on the basis of incisive spectral analyses 5 (Scheme 3 ).

Interestingly, 5-methylbenzo[c]phenanthrene $\mathbf{1 3}$ and the Wittig salt $\mathbf{1 4}$ derived from it also served as the precursor for the synthesis of tribenzocorannulene 5 . Wittig coupling between 14 and 4-methylnaphthaldehyde gave 19 which on photocyclization led to the naphtho[1,2-f]picene derivative 20 (Scheme 4). The methyl group in $\mathbf{2 0}$ was again elaborated to the aldehyde $\mathbf{2 1}$ and further to the FVP precursor 22. As planned, FVP on 22

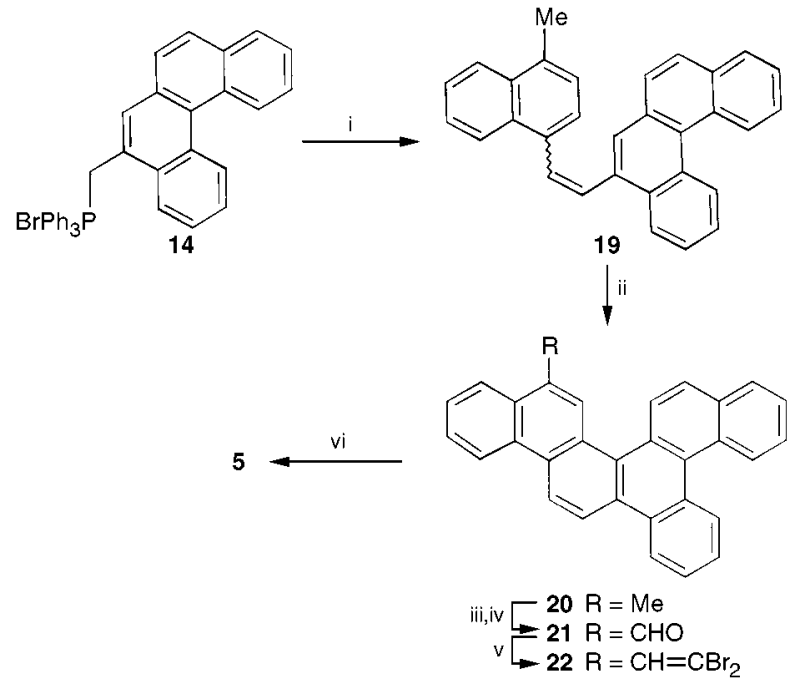

Scheme 4 Reagents and conditions: i, 4-methylnaphthaldehyde, $\mathrm{Cs}_{2} \mathrm{CO}_{3}$, $\mathrm{Pr} \mathrm{OH} ; \mathrm{ii}, h v, \mathrm{I}_{2}, \mathrm{C}_{6} \mathrm{H}_{6}$, propylene oxide, $50 \%$ (2 steps); iii, $\mathrm{NBS}, \mathrm{CCl}_{4}, 45 \%$; iv, $\left(\mathrm{Bu}_{4} \mathrm{~N}\right)_{2} \mathrm{Cr}_{2} \mathrm{O}_{7}, \mathrm{CHCl}_{3}, 70 \%$; v, $\mathrm{CBr}_{4}, \mathrm{PPh}_{3}, \mathrm{Zn}, \mathrm{CH}_{2} \mathrm{Cl}_{2}, 55 \%$; vi, FVP, $1150{ }^{\circ} \mathrm{C}, 1-2 \%$. furnished the desired tribenzocorannulene $\mathbf{5}$, which was spectroscopically characterised (Scheme 4).5,6

In short, we have accomplished the syntheses of bowl-shaped benzocorannulenes 3-5 from appropriate polycyclic aromatics employing FVP as the key step, in which a five- and a sixmembered rings are sequentially formed. The precursor polycyclic platforms were assembled from simple aromatic starting materials through an iterative sequence involving Wittig olefination and photocyclization steps. Notwithstanding the low yields in the final FVP step, which is not uncommon for such cyclizations, 1,2 this work demonstrates the generality of our approach and sets the stage for the synthesis of $\mathbf{1}$ and $\mathbf{2}$.

We thank JNCASR for financial support and the SIF facility at I.I.Sc for high field NMR data. One of us (P. V. V. S. S.) thanks CSIR for a research fellowship. We thank Professor L. T. Scott for generously providing copies of spectra for comparison purposes.

\section{Notes and references}

1 Reviews: (a) R. Faust, Angew. Chem., Int. Ed. Engl., 1995, 34, 1429; (b) L. T. Scott, Pure Appl. Chem., 1996, 68, 291; (c) G. Mehta and H. S. P. Rao, in Advances in Strain in Organic Chemistry, ed. B. Halton, JAI, London, 1997, vol. 6; (d) G. Mehta and H. S. P. Rao, Tetrahedron, 1998, 53, 13 325; (e) L. T. Scott, Pure Appl. Chem., 1999, 71, 209.

2 G. Mehta, S. R. Shah and K. Ravikumar, J. Chem. Soc., Chem. Commun., 1993, 1006; G. Mehta and K. Venkateswara Rao, Synlett, 1995, 319; G. Mehta, K. Venkateswara Rao and K. Ravikumar, J. Chem. Soc., Perkin Trans. 1, 1995, 1787; G. Mehta, G. V. R. Sharma, M. A. Krishna Kumar, T. V. Vedavyasa and E. D. Jemmis, J. Chem. Soc., Perkin Trans. 1, 1995, 2529; G. Mehta, G. Panda, R. D. Yadav and K. Ravikumar, Indian J. Chem., Sect. B, 1997, 36, 301; G. Mehta and G. Panda, Tetrahedron Lett., 1997, 38, 2145; G. Mehta and G. Panda, Chem. Commun., 1997, 2081; G. Mehta, G. Panda, S. R. Shah and A. C. Kunwar, J. Chem. Soc., Perkin Trans. 1, 1997, 2269; G. Mehta, G. Panda and P. V. V. S. Sarma, Tetrahedron Lett., 1998, 39, 5835.

3 G. N. Sastry, E. D. Jemmis, G. Mehta and S. R. Shah, J. Chem. Soc., Perkin Trans. 2, 1993, 1867.

4 W. H. Laarhoven, Th. J. H. M. Cuppen and R. J. F. Nivard, Tetrahedron, 1970, 26, 4865 .

5 All new compounds reported here were fully characterised on the basis of their spectral (UV, IR, 2D ${ }^{1} \mathrm{H}$ and ${ }^{13} \mathrm{C}$ NMR, MS) and analytical data. Selected data for 3: $\mathrm{mp} 253{ }^{\circ} \mathrm{C} ; \lambda_{\max }(\mathrm{MeOH}) / \mathrm{nm} \mathrm{305,} \mathrm{275,} 260$ and 240; $\delta_{\mathrm{H}}\left(300 \mathrm{MHz} ; \mathrm{CDCl}_{3}\right), 8.68(2 \mathrm{H}, \mathrm{dd}, J 6$ and 3.3$), 8.26(2 \mathrm{H}, \mathrm{d}, J 8.7), 7.95$ $(2 \mathrm{H}, \mathrm{d}, J 8.7), 7.84(4 \mathrm{H}, \mathrm{ABq}, J 8.7), 7.76(2 \mathrm{H}, \mathrm{dd}, J 5.7$ and 3.3$) ; \delta_{\mathrm{C}}(75$ $\mathrm{MHz} ; \mathrm{CDCl}_{3}$ ) 137.6 (qC), 135.4 (qC), 134.6 (qC), 133.1 (qC), 130.8 (qC), $130.5(\mathrm{qC}), 128.9(\mathrm{qC}), 127.5(\mathrm{CH}), 127.3(\mathrm{CH}), 127.1(\mathrm{CH}), 126.9$ $(\mathrm{CH}), 125.1(\mathrm{CH})$ and $124.3(\mathrm{CH}) ; \mathrm{m} / \mathrm{z} 300\left(\mathrm{M}^{+}\right)$. For 4: $\mathrm{mp}>250{ }^{\circ} \mathrm{C}$ (decomp.); $\lambda_{\max }(\mathrm{MeOH}) / \mathrm{nm} 319,272,257$ (sh), 242 (sh); $\delta_{\mathrm{H}}(300 \mathrm{MHz}$; $\left.\mathrm{CDCl}_{3}\right) 9.41(2 \mathrm{H}, \mathrm{d}, J 8.4), 8.83(2 \mathrm{H}, \mathrm{d}, J 7.5), 8.35(2 \mathrm{H}, \mathrm{d} J 8.7), 8.01$ $(2 \mathrm{H}, \mathrm{d}, J 8.4), 7.91(2 \mathrm{H}, \mathrm{s}), 7.88-7.77(4 \mathrm{H}, \mathrm{m}) ; \delta_{\mathrm{C}}\left(75 \mathrm{MHz} ; \mathrm{CDCl}_{3}\right) 136.7$ (qC), 134.2 (qC), 134.0 (qC), 133.9 (qC), 133.7 (qC), 130.2 (qC), 128.5 $(\mathrm{qC}), 127.8(\mathrm{CH}), 127.5(\mathrm{CH}), 127.1(\mathrm{CH}), 127.0(\mathrm{CH}), 126.5(\mathrm{CH})$, $125.5(\mathrm{CH}), 124.5(\mathrm{qC}), 123.9(\mathrm{CH}) ; \mathrm{m} / z 350\left(\mathrm{M}^{+}\right)$. For 5: $\lambda_{\max }(\mathrm{MeOH}) /$ $\mathrm{nm} \mathrm{347,} \mathrm{334,} \mathrm{279,} \mathrm{252;} \delta_{\mathrm{H}}\left(400 \mathrm{MHz} ; \mathrm{CDCl}_{3}\right) 9.41(2 \mathrm{H}, \mathrm{d}, J 8), 8.86(2 \mathrm{H}$, $\mathrm{d}, J 7.2) 8.73(2 \mathrm{H}, \mathrm{dd}, J 6.4$ and 3.6), $8.45(4 \mathrm{H}, \mathrm{ABq}, J 8.4), 7.87(2 \mathrm{H}, \mathrm{d}$, $J$ 8), $7.83\left(2 \mathrm{H}, \mathrm{d}, J\right.$ 9.2), $7.79(2 \mathrm{H}, \mathrm{dd}, J 6$ and 3.2$) ; \mathrm{m} / \mathrm{z} 400\left(\mathrm{M}^{+}\right)$.

6 Mono- 3 and tri-benzocorannulene 5 reported here have been prepared previously by Scott et al. [ref. 1(b), (e)] following entirely different routes. See also: B. McMahon, B.S. Thesis, Boston College, 1997; C. C. McComas, B.S. Thesis, Boston College, 1996. Since the details of this work are not published, we have provided here the spectral data and also compared the spectra of our synthetic compounds with theirs. Dibenzocorannulene $\mathbf{4}$ has been prepared for the first time.

7 D. L. Nagel, R. Kupper, K. Antonson and L. Wallcave, J. Org. Chem., 1977, 42, 1977. 